\title{
Timely-activated 316L stainless steel: a low cost, durable and active electrode for oxygen evolution
}

\section{reaction in concentrated alkaline environments}

Florian Moureaux ${ }^{a, b}$, Philippe Stevens ${ }^{b}$, Gwenaëlle Toussaint ${ }^{b}$ and Marian Chatenet ${ }^{a}$ *

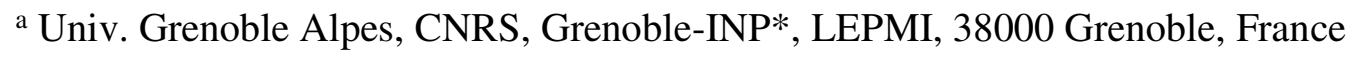

${ }^{\mathrm{b}}$ Department Electric Equipment Laboratory (LME), EDF R\&D, Avenue des Renardières, 77818 Morêt-sur-Loing CEDEX, France

* Institute of Engineering, Univ. Grenoble Alpes

\section{AUTHOR INFORMATION}

\section{Corresponding Author}

* Marian.Chatenet@grenoble-inp.fr 


\section{ABSTRACT}

316L stainless steel (SS) electrodes were activated for the oxygen evolution reaction (OER) without addition of hetero-elements or incorporation of deposits at their surface. Such activation was either spontaneous (in situ: slow surface modification upon OER operation), or accelerated (ex situ, by alternating potential steps at low/high potential). Both techniques enable formation of a catalytic surface from the SS bulk components in experimental conditions close to those of usage, which guarantees long-term-stability and high-activity of the surfaces. Ex situ-activated electrodes show comparable performances than in situ-activated electrodes, the resulting OER activities in $\mathrm{KOH}$ electrolytes being high compared to other noble-metal-free electrocatalysts. Activated 316L electrodes are remarkably stable in long-term OER operation (> $300 \mathrm{~h}$ ). Therefore, cheap and widely-available activated-SS may be very competitive OER materials for alkaline water electrolyzers. These results open the way to the development of highly-active and low-cost OER materials for hydrogen production, or metal-air batteries.

\section{TOC GRAPHICS}




\section{Electrochemical}

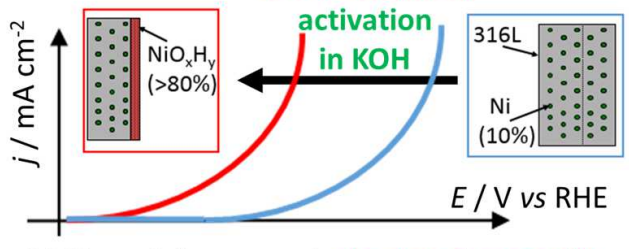

316L stainless-steel electrochemicallyactivated in $\mathrm{KOH}$ exhibits $\mathrm{Ni}$-enriched surface \& promotes fast \& durable OER 


\section{Introduction}

One cannot ignore the deleterious issues of global warming and the means that mankind can use to try to attenuate emissions of greenhouse gases that are at its origin [1]. Fossil fuels should no longer be extensively extracted and should wherever possible be substituted with a clean energy vector: electricity produced from renewable energy (of solar, wind or water origin) is an obvious solution, and is undergoing rapid growth. However, injecting large amounts of intermittent renewable electricity may destabilize the electrical grid if it is not consumed at the same rate that it is produced. One solution to this electrical engineering issue would be to efficiently store renewable electricity when it is less needed, so that the grid can return benefit from this storage for peaks in electricity demand [2]. There are many technological solutions to store electrical energy; one of the most widespread and most efficient of them is pumped hydro, but one cannot implement it everywhere and most sites where it could prove viable are already equipped. Electrochemical storage in batteries is another well-studied option [3, 4], e.g. in Zn-air batteries not using any noble catalysts [5], which could provide a solution for short to medium storage times, typically between 15 minutes and 4 hours. For longer storage times or for large amounts of electricity, power-to-hydrogen could be a solution, at least for use in conjunction with the other storage means mentioned above.

Hydrogen is a clean energy carrier when its production does not involve fossil fuels, which is where water electrolysis has an important role to play $[6,7]$. Although molecular hydrogen $\left(\mathrm{H}_{2}\right)$ is usually the product of interest in water electrolysis, the research community soon realized that it is the other product of water splitting, molecular oxygen $\left(\mathrm{O}_{2}\right)$ that limits the reaction, owing to the very sluggish oxygen evolution reaction (OER) on most electrocatalysts. In addition, the experimental conditions experienced by OER anodes in water electrolyzers are extremely 
aggressive, resulting in severe durability issues. Today, the majority of the research in the world is focused on water electrolyzers using proton-exchange membranes (PEM), which exhibit high initial performance $[8,9]$. However, the acidic environment of the PEM makes the use Pt-group metal (PGM) electrocatalysts [8, 10-15] quasi-mandatory, these elements being of very limited abundance, and of questionable stability [16-20]. Most non-PGM electrocatalysts [21-32] are more abundant and therefore more desirable, but these materials are generally less active and durable than PGMs in acidic environments. For this reason, alkaline water electrolysis is a subject of rising interest, as it might be the only water electrolysis technology with sufficient electrical performances that is compatible with a widespread deployment.

Alkaline water electrolysis is not a new technology, as it is the historical large-scale means of “clean" hydrogen production [23, 33-36]. Nickel-based oxides [37-39] (either used "alone" or in combination with a suitable support [40]) or cobalt-based oxides [41-45] are often considered amongst the best electrode materials for alkaline OER [27, 46-48]. One widely-used strategy to prepare stable OER electrocatalysts is to deposit a thin "active layer" of these metals/oxides on the surface of an electronically conductive substrate, e.g. carbon $[38,47]$, conducting oxides [9, 49-55] or steels [56-59]. Although electrocatalysts prepared on such electrodes can be very active, their long-term durability is rarely reported and is open to question, in particular in strong bases: except from Li's work [60], dealing with Janus Ni-Co-P nanowires, which were demonstrated for $3000 \mathrm{~h}$ in water electrolysis, durability studies of the literature usually do not exceed a few 10 or at best a few 100 of $\mathrm{h}$ in operation for such electrocatalysts. This has been demonstrated, for example for carbon surfaces [61-64], carbon-supported electrocatalysts [6570] or metal and their oxides [18, 19]. In addition, when stainless steel (hereafter denoted as "SS") is used as a conducting substrate only, the many transition metals that make them up turn 
out to be active for the (alkaline) OER, and they are not put to beneficial use. This is why some reports now focus on the use of stainless steels as "simple and easy" materials for the alkaline OER. In this case, the active (and stable) layer of the OER electrode originate from the components of the bulk material. This active layer plays the role of an "active passivation layer", i.e. a layer that exhibits antagonistic properties of high electrocatalytic activity together with high stability towards corrosion through passivation. A very good example in this direction is described in the previous work of the authors, where 316L SS was activated in situ by a simple long-term OER operation in concentrated $\mathrm{LiOH}$ electrolyte, producing a very active and stable surface (stability was demonstrated for $3000 \mathrm{~h}$ in OER operation) to promote the positive reaction of water splitting in $5 \mathrm{M} \mathrm{LiOH}$ (as a third charging electrode in an aqueous $\mathrm{Li}$-air battery) [71]. Other examples have emerged in the literature, in particular from Schafer's group in Germany [72-76] and others [77], as recalled in a recent review [78]. One of the very important characteristic of stainless steel electrodes activated in situ by "simple (long-term) operation" in the electrolyte of operation, is their "self-healing ability", which accounts for their long-term durability. Because the active layer is made from controlled corrosion of the underlying bulk alloy (which also protects it), it is capable of re-forming later on if, by accident, the active layer is detached (for example under the mechanical pressure of harsh gas evolution) $[71,77]$. Another solution is to perform an ex situ treatment to generate a tailored surface layer that is prone to catalyze the reaction of interest. The group of Schafer made significant progresses in this direction for OER electrocatalysis [72, 74, 75], soon followed by others [79], the strategy being also used for alternative applications, e.g. to design supercapacitors [80] or Liion battery [81] electrodes. 
Following the work on activated 316L SS electrodes for OER in concentrated LiOH electrolytes [71], the present paper investigates the same type of materials, but for use in $\mathrm{KOH}$ electrolyte. The main objective of this contribution is to extend the concepts to more widely-used electrolytes and in particular to assess whether these electrodes could be useful in an industrial alkaline water electrolysis process, most of which use aqueous $\mathrm{KOH}$ electrolyte (at least prior the introduction of anion-exchange membranes in these technologies [82]), or as third electrode in aqueous metal-air batteries (e.g. Zn-air). In addition, knowing that in the previous work of the authors [71], the in situ activation in $5 \mathrm{M} \mathrm{LiOH}_{(\mathrm{aq})}$ lasted $c a .250 \mathrm{~h}$, which is not practical, a procedure for a fast ex situ activation of the $316 \mathrm{~L} \mathrm{SS}$ electrode in $5 \mathrm{M} \mathrm{LiOH}$ is proposed. The soobtained materials were benchmarked to home-made CoOx deposits, known to be very active for the OER $[41,45,56,83,84]$. Finally, because accelerated activation in LiOH electrolytes may not be practical, a procedure where the 316L SS surfaces were activated in $\mathrm{KOH}$ was analyzed to check whether such electrodes present the same morphology, composition and activity as those activated in LiOH electrolytes. All the experimental findings (activity reached and stability of the performances) will be supported by thorough physicochemical characterizations, namely scanning electron microscopy (SEM), X-ray diffraction (XRD) and Raman spectrometry, so as to draw conclusions about composition-structure/activity-durability relationships.

\section{Experimental}

Most of the experimental procedures are derived from previous works [71, 85] and the readers are directed to these documents for more details. Specific to this study are the preparation and 
characterizations of cobalt oxides deposits on $316 \mathrm{~L}$ stainless steel substrate. Two types of $\mathrm{CoO}_{\mathrm{x}}$ deposition technics were performed.

The electrochemical deposition of $\mathrm{CoO}_{x}$ were prepared from $0.3 \mathrm{M} \mathrm{CoSO}_{4}$ aqueous electrolyte at $T=50^{\circ} \mathrm{C}$, by applying a cathodic current density of $j=-1 \mathrm{~mA} \mathrm{~cm}^{-2}$ (geometric) during $t=1500 \mathrm{~s}$ on the desired 316L substrate, which should (in theory) yield a deposit thickness of $c a .500 \mathrm{~nm}$ of cobalt. The layer obtained was then thermally annealed (under air) using a $1^{\circ} \mathrm{C} \min ^{-1} \mathrm{ramp}$ from $T=25^{\circ} \mathrm{C}$ to $T=400^{\circ} \mathrm{C}$, followed by a $2 \mathrm{~h}$ step at $T=400^{\circ} \mathrm{C}$ and then a cooling ramp at $1^{\circ} \mathrm{C} \min ^{-1}$ down to $T=25^{\circ} \mathrm{C}$.

Sol-gel deposition of $\mathrm{CoO}_{x}$ was also experimented by following a procedure developed by Singh et al.[86]. More specifically, the precursors of the oxides layer were blended in stoichiometric amounts $\left(c a .0 .1 \mathrm{M} \mathrm{CoSO}_{4}+0.2 \mathrm{M} \mathrm{LiOH}\right)$, resulting in a $\mathrm{Co}(\mathrm{OH})_{2}$ precipitate. The latter was filtered, abundantly rinsed with ultrapure water $(18.2 \mathrm{M} \Omega \mathrm{cm},<3 \mathrm{ppb}$ total organic carbon, Millipore $\left.^{\circledR}\right)$ and dried for $24 \mathrm{~h}$ in room conditions. The powder obtained was then dissolved in acetic acid to produce a gel of $\mathrm{Co}\left(\mathrm{CH}_{3} \mathrm{OO}\right)_{2}$, which was painted on the 316L substrate, and finally thermally-annealed under air for $t=30 \mathrm{~min}$ at $T=350^{\circ} \mathrm{C}$ to convert the cobalt acetate to $\mathrm{Co}_{3} \mathrm{O}_{4}$.

In both cases, and also for the bare $316 \mathrm{~L}$ substrate, the $\mathrm{CoO}_{\mathrm{x}} / 316 \mathrm{~L}$ surfaces obtained were thoroughly characterized by scanning electron microscopy (SEM, HIROX SH-1500 SEM) coupled with elemental X-Ray energy dispersive spectrometry (X-EDS, XFLASH 410-H semiconductor Silicon Drift Detector, controlled with Esprit ${ }^{\circledR}$ V1.8), X-Ray diffraction (XRD, PANalytical X'Pert Pro MPD operating at $45 \mathrm{kV}$ and $40 \mathrm{~mA}$ - Bragg-Brentano configuration, $\mathrm{Cu} \mathrm{K} \alpha$ radiation), Raman spectroscopy (Renishaw ${ }^{\circledR}$ Raman microscope, operating with an argon 
LASER at $540 \mathrm{~nm}$ ) and X-Ray photoelectron spectroscopy (XPS, performed on a XR3E2 apparatus (Vacuum Generator) using a $\mathrm{Mg} \mathrm{K} \alpha$ source $(1253.6 \mathrm{eV})$ and a hemispherical analyzer at constant pass energy of $30.0 \mathrm{eV})$.

The materials were also tested for their electrochemical activity and durability. The electrochemical characterizations were performed in a three-electrode electrochemical cell as previously described [71]. Although experimentally, the reference electrode used was a mercurymercury oxide electrode $(\mathrm{Hg}-\mathrm{HgO}, 1 \mathrm{M} \mathrm{KOH})$, all the data presented herein are expressed versus the reversible hydrogen electrode (RHE), so that the $\mathrm{pH}$ effect is corrected for the three aqueous alkaline electrolytes characterized here: $1 \mathrm{M} \mathrm{KOH}, 5 \mathrm{M} \mathrm{KOH}$ and $5 \mathrm{M} \mathrm{LiOH}$. Given that measuring the $\mathrm{pH}$ of strongly alkaline solutions is not straightforward, the $\mathrm{pH}$ values determined by Pound et al. [87] (Table 1) were used. From these, the potential values experimentally measured versus $(\mathrm{Hg}-\mathrm{HgO}, 1 \mathrm{M} \mathrm{KOH})$ were converted on the RHE.

Table 1: values of the $\mathrm{pH}$ of the electrolyte solutions considered in the study, as determined by Pound et al. [87].

\begin{tabular}{|c|c|c|}
\hline Electrolyte & $\mathrm{pH}$ & $E_{\mathrm{RHE}} \mathrm{vs.} E_{\mathrm{Hg} / \mathrm{HgO}-1 \mathrm{M} \mathrm{KOH}}$ \\
\hline $5 \mathrm{M} \mathrm{LiOH}$ & 14.5 & 0.95 \\
\hline $5 \mathrm{M} \mathrm{KOH}$ & 15.3 & 1.00 \\
\hline $1 \mathrm{M} \mathrm{KOH}$ & 13.9 & 0.92 \\
\hline
\end{tabular}

\section{Results and discussion}


3.1. Preamble: instability of electrodes prepared by electrodeposition of a foreign layer at the surface of a SS 316L electrode and interest of "self-activated" electrodes

The results shown in Figure 1 suggests that hetero-deposits of $\mathrm{CoO}_{\mathrm{x}}$ may not be stable on the long-term for the OER. In particular, the highly-active $\mathrm{CoO}_{\mathrm{x}}$ deposits investigated here are severely modified by long-term oxygen evolution in $5 \mathrm{M} \mathrm{LiOH}$ electrolyte. Two processes are at stake: (i) the very oxidizing conditions experienced during OER promote the "corrosion" of the $\mathrm{CoO}_{\mathrm{x}}$ deposit and (ii) the gas evolution which induces the mechanical disintegration of the layer from its support. Such mechanical disintegration occurs in particular when the interaction of the active layer with its support is not sufficiently strong, which is obvious for the sol-gel $\mathrm{CoO}_{\mathrm{x}}$ deposit in Figure 1. Once the layer has been completely destroyed, only the substrate remains and the OER activity decreases (at least until the 316L SS substrate self-activates upon operation, which takes time, as detailed below). In addition, the deep modifications of the electrodeposited $\mathrm{CoO}_{\mathrm{x}}$ electrode surface (Figure 1B,C) raises the question of the relevance of tightly controlling the initial electrode composition and texture as it will likely be (severely) modified (if not destroyed) in usage, with no hope of its re-formation in operation. 


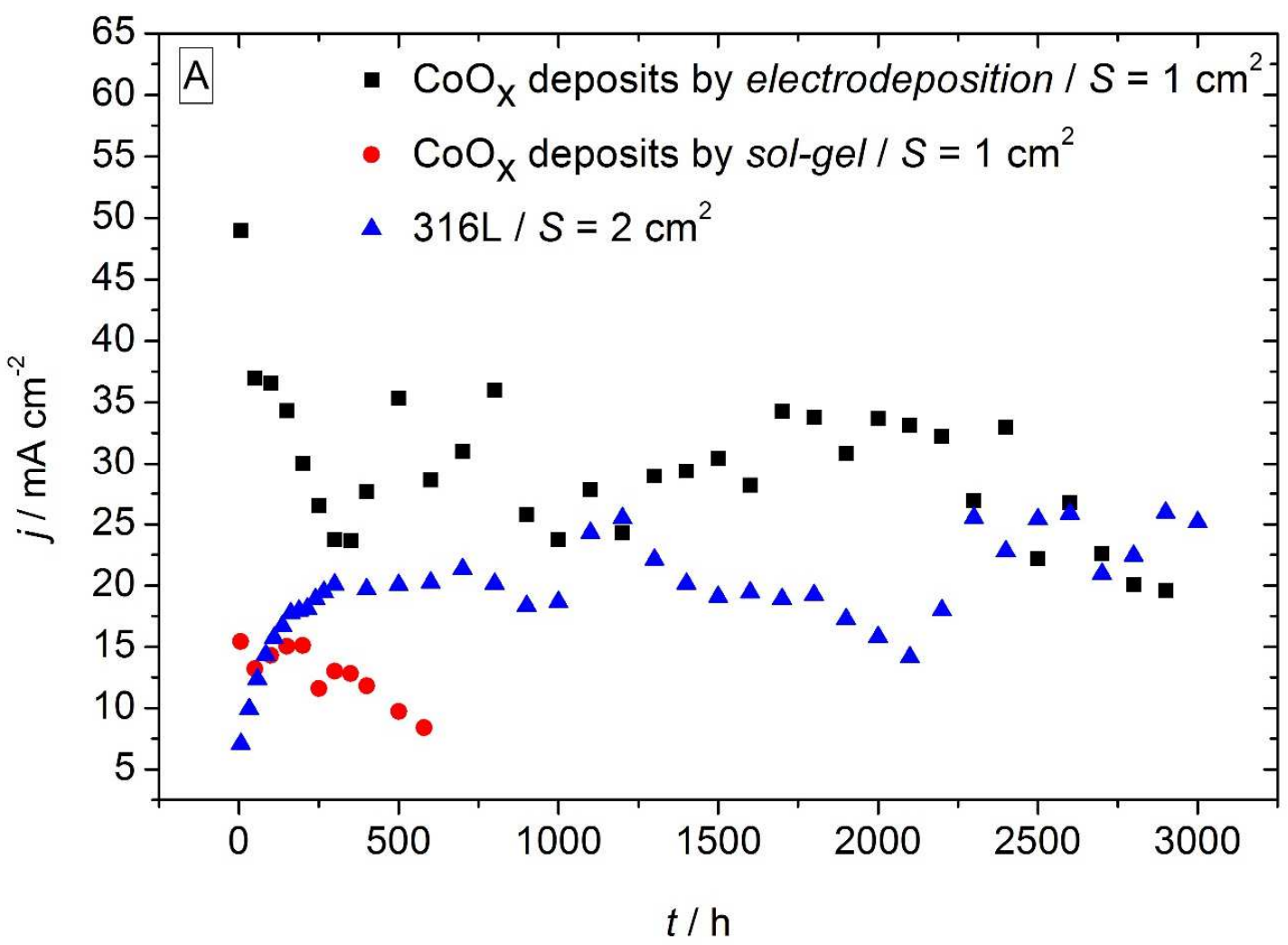




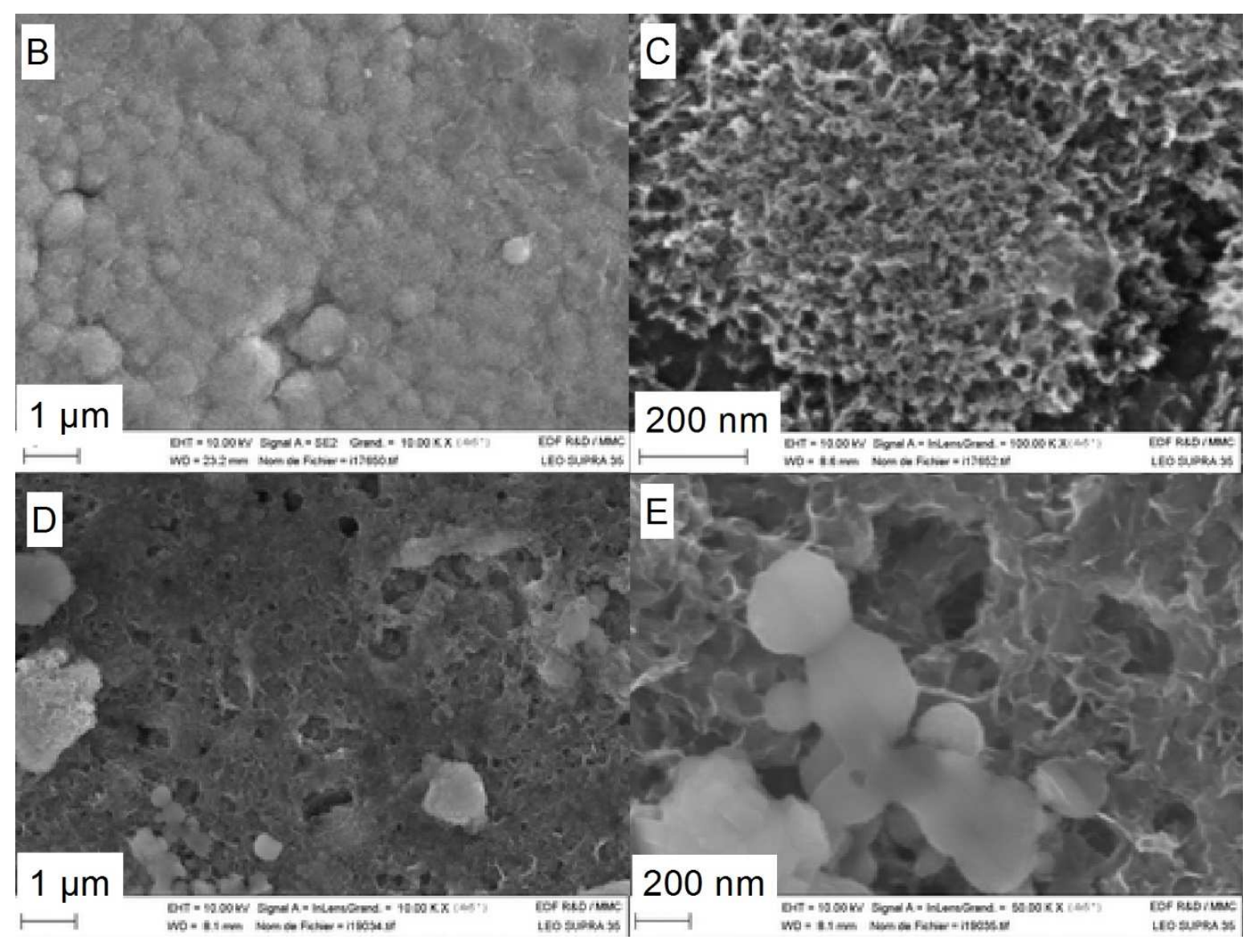

Figure 1: (A) Time-dependent performance of OER electrodes consisting of CoOx deposits

prepared either by electrodeposition or by sol-gel chemistry at the surface of a 316L SS surface,

during a 3000 h OER test performed at $E=1.75 \mathrm{Vvs}$. RHE in $5 \mathrm{M} \mathrm{LiOH}$ at $\mathrm{T}=25^{\circ} \mathrm{C}$;

uncompensated Ohmic-drop. Their activity irreversibly decreases over time, owing to

modifications of the CoOx deposit and especially its detachment from the SS surface. The

performances of the SS support (316L) are also given for comparison. Representative

micrographs of the surface of the electrodeposited CoOx deposit $(B, C)$ before and $(D, E)$ after

the 3000 h of test. The surface of the CoOx deposit is deeply modified upon operation. Adapted

from [85] with permission from Univ. Grenoble-Alpes. 
The authors believe that these problems will come upon any porous active deposit used in gas evolution reactions (in particular the OER). In addition, the stability of the layers formed "ex situ" (and using elements that do not enter the composition of the bulk substrate) at the surface of steels for operation in water spitting has previously been questioned [78]. The answer may come from the formation of a stable, homogenous and adherent catalytic layer on the surface of steel electrodes by a direct corrosion/passivation mechanism of this surface during OER, as previously demonstrated. This strategy was successfully adopted by the authors for the OER in concentrated LiOH electrolyte [71, 85] (Figure 2). In that study, remarkable stability and OER activity was demonstrated. However, the activation of the 316L SS electrode in LiOH electrolyte was very long $(c a .250 \mathrm{~h})$, which is a clear limitation for a practical application. Besides, these remarkable OER performances were obtained in $5 \mathrm{M} \mathrm{LiOH}$ electrolyte, and it would be interesting to check whether these materials are also active and durable for operation in $\mathrm{KOH}$ electrolyte, for a possible application in water electrolysis, or in rechargeable aqueous metal-air batteries (e.g. Znair). Results in this direction are presented in the next sections.
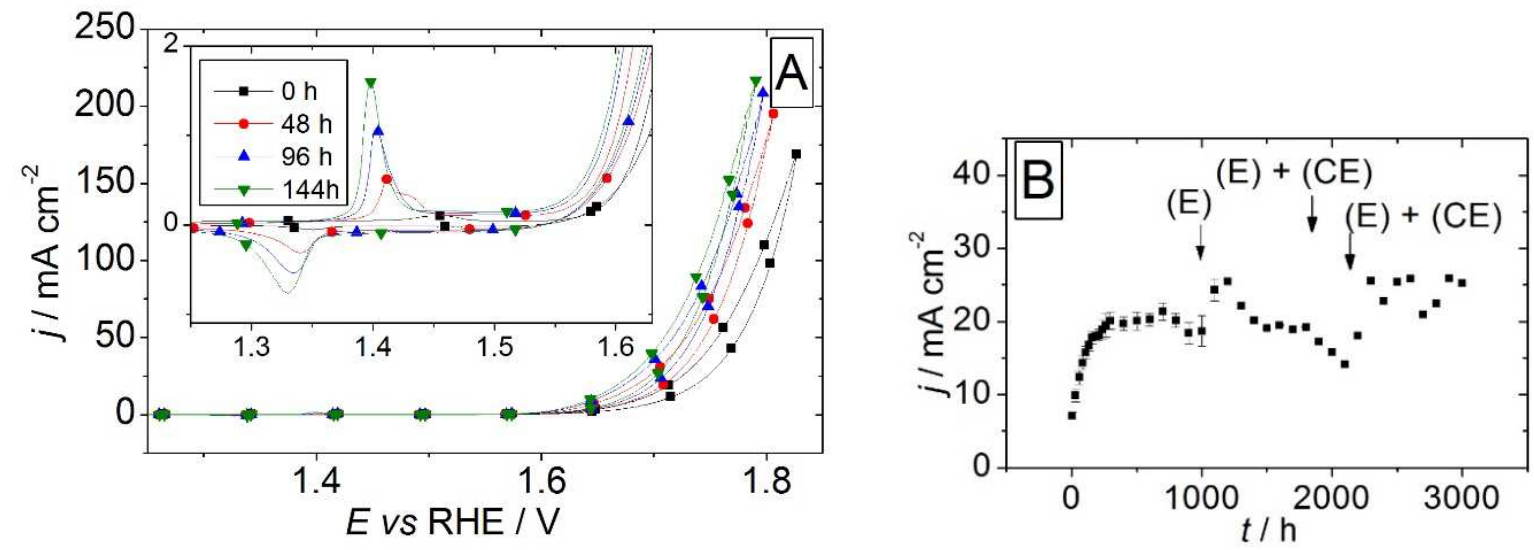

Figure 2: (A) Cycling voltamperograms monitored for a 316L SS electrode in $5 \mathrm{M} \mathrm{LiOH}$ at T= $25^{\circ} \mathrm{C}$ during the first $144 \mathrm{~h}$ of operation as an OER electrode (constant polarization, $E=1.70 \mathrm{~V}$ 
vs. RHE ; uncorrected from Ohmic drop) revealing the substantial "activation" of the surface. (B) After the initial in situ "activation", the performances maintain for very long term (the variations in current density over time originated by the gradual failure of the reference and/or counter-electrode; as a result, the electrolyte $(E)$ and counter-electrode (CE) had to be periodically replaced). Adapted from [71], with permission from Elsevier.

\subsection{Ex situ accelerated activation of a 316L SS electrode}

The formation of a Ni-rich "active layer" that results in a high OER activity but which also protects the underlying 316L SS electrode (Figure 2) is explained by the following reaction mechanism during the "early" stages (i.e. the first $250 \mathrm{~h}$ or OER operation) of the process [71, 85]: the first step is an anodic dissolution of the 316L metals (forming mainly nickel, iron and chromium cations, the base elements of 316L SS) followed by their possible precipitation owing to their low solubility in the $5 \mathrm{M} \mathrm{LiOH}$ electrolyte. In particular, the different solubility values of $\mathrm{Cr}, \mathrm{Fe}$ and $\mathrm{Ni}$ cations produce the peculiar composition of this layer $(82.5 \mathrm{at} \% \mathrm{Ni}, 10$ at $\% \mathrm{Fe}, 7.5$ at\% $\mathrm{Cr}$, i.e. very different from the base composition of bulk 316L SS: $c a .10-14$ at $\% \mathrm{Ni}, c a .70$ at\% Fe, ca. 16-18.5 at\% Cr). As a consequence, the Ni-rich layer so-obtained possesses the remarkable combined properties of passivation, semi-conductivity and electrochemical OER activity [71, 88], the latter likely originating from a so-called hypo-hyper $d$ interbonding effect put forth by Jaksic et al.[89] and then Micoud et al. [90]. As such, the passive film is capable of protecting the underlying OER electrode in the course of the continuous OER operation, which explains its very moderate thickness even after $3000+$ hours of operation in $5 \mathrm{M} \mathrm{LiOH}$ (below 50 $\mathrm{nm})$ [71]. On the contrary, the fact that this layer protects the underlying 316L SS raises 
questions about the reasons why such a layer forms. At that stage, the authors postulate that it is the initial characterization steps (see Figure 2A) that led to the formation of this layer. As such, it is anticipated that alternating the potential of the 316L electrode between "low" and "high" values in a similar electrolyte $(5 \mathrm{M} \mathrm{LiOH})$ would lead to the same surface structure/composition of the electrode, and therefore to the same electrochemical properties (activity and robustness).

This study aims at first to accelerate the formation of the Ni-rich passive (to limit corrosion) and active (to enable fast OER) film at the surface of the $316 \mathrm{~L}$ electrode. Being admitted that it is the alternation of the electrode potential between "low" and "high" potential values (during the characterization steps of Figure 2A) that led to the active layer, the protocol of ex situ accelerated activation was built as follows.

- Step 1: a sequence of 10 min polarization at $E=1.53 \mathrm{~V} v s$. RHE (a potential above the domain of formation of NiIII, see Figure 2A) followed by 5 min at $E=0.93 \mathrm{~V} v s$. RHE (a potential below the domain of formation of NiII, see Figure 2A), overall repeated twice;

- Step 2: two voltamperometric cycles at $v=5 \mathrm{mV} \mathrm{s}^{-1}$ performed in the range $0.93<E<$ $1.93 \mathrm{~V} v s . \mathrm{RHE}$; the potential is therefore, again, scanned above/below the NiII/NiIII redox transition;

- The sequences of Step 1 and then Step 2 was repeated 12 times, the entire protocol lasting overall $8 \mathrm{~h} 40 \mathrm{~min}$.

The rationale of these alternations of "high" / "low" potential values was to favor the electrochemical dissolution/chemical precipitation of the metal cations of the $316 \mathrm{~L}$ electrode at high potential and to reduce the surface species at low potential, to re-enable some dissolution of 
the electrode and to build in this manner a "thick-enough" (and therefore stable-enough protection of the underlying bulk $316 \mathrm{~L}$ material) active layer.

After such accelerated activation, the 316L SS electrodes were firstly tested for the OER in $5 \mathrm{M}$ $\mathrm{LiOH}$ electrolyte, so as to compare their activity and stability with regards to the electrodes activated in situ (see Figure 2) in a time-consuming procedure ( $c a .250$ h). Figure 3 clearly demonstrates that the activity of 316L SS electrodes activated ex situ by this accelerated procedure is similar to that ultimately reached by the electrodes activated in situ. Interestingly, these high performances are reached much faster than the $200 \mathrm{~h}$ of operation required for the in situ activated electrodes. One should note however that the activity of the ex situ activated electrode slightly increases in the first $50 \mathrm{~h}$ of the OER durability test, probably owing to a stabilization and/or thickening of the surface film during the initial period of the OER operation.

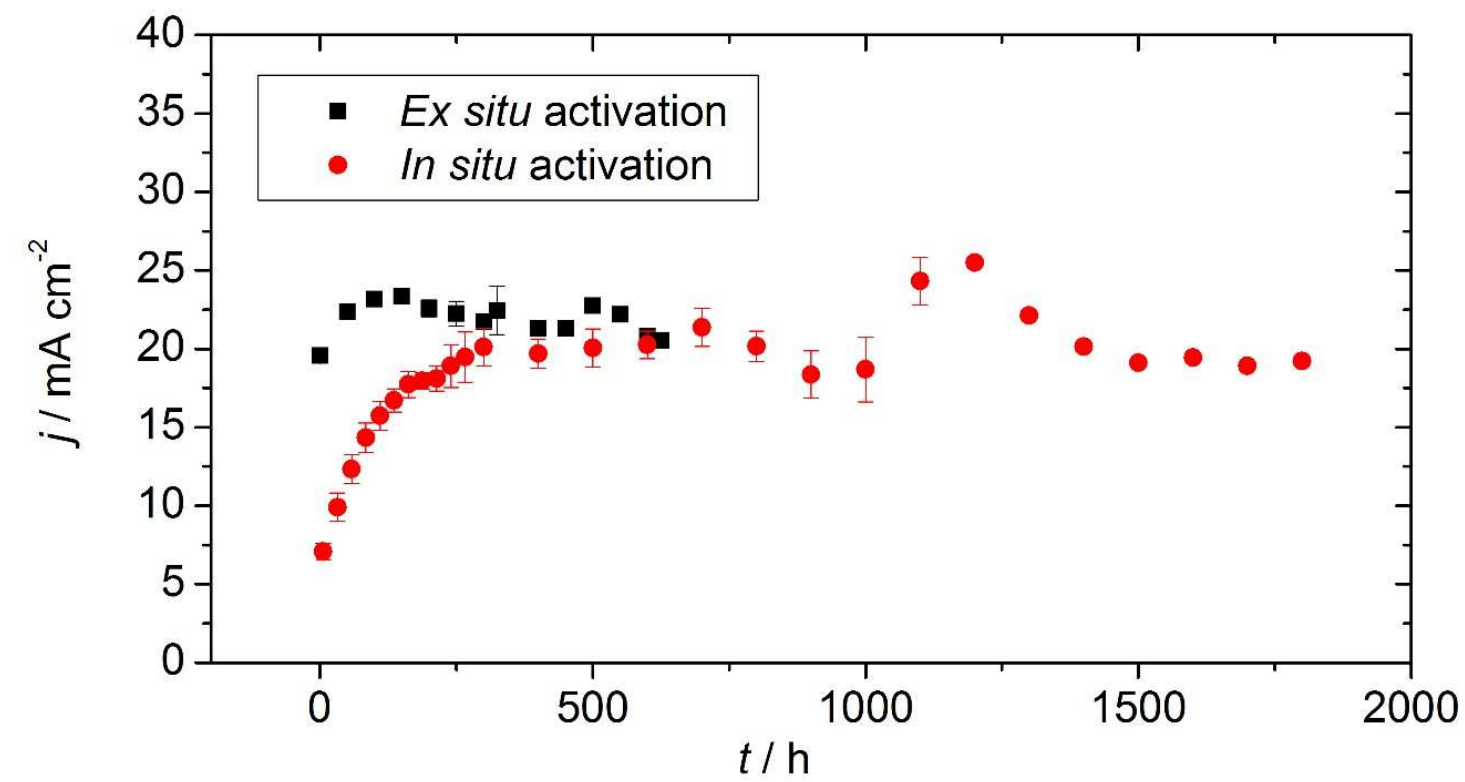

Figure 3: Comparison of the OER performances in $5 \mathrm{M} \mathrm{LiOH}$ at $\mathrm{T}=25^{\circ} \mathrm{C}$ of the $316 \mathrm{~L} \mathrm{SS}$ electrodes OER (test performed at $E=1.75 \mathrm{Vvs}$. RHE) after accelerated activation and of the in 
situ activated 316L SS electrode (see Figure 2). Statistical data were obtained for duration of tests below $350 \mathrm{~h}$ for the $316 \mathrm{~L}$ SS electrodes after accelerated activation, and up to $1100 \mathrm{~h}$ for in situ activated electrodes. The trace relative to the in situ activated $316 \mathrm{~L}$ SS electrode is the same as that presented in Figure $2 B$.

The latter behavior (activation/corrosion) of the electrodes during OER operation in $5 \mathrm{M} \mathrm{LiOH}$ was characterized by measuring the surface charge relative to the NiII/NiIII redox couple as a function of the time of operation, this coulometry assessment being calculated from the cyclic voltammograms performed periodically during the OER test. Figure 4 demonstrates that the NiII/NiIII redox couple coulometry of the ex situ activated 316L electrode is more stable versus time, which denotes slower roughening (or oxides growth) for this electrode. The thickness of the "active oxides layer" formed versus the time of operation can also be estimated from Figure 4: it grows more slowly in the case of the ex situ activated 316L electrode, which denotes for an overall better resistance of this electrode towards corrosion during OER operation in $5 \mathrm{M} \mathrm{LiOH}$ electrolyte (the link between the surface capacity/coulometry of the NiII/NiIII redox couple and the consumption of the base metals of the $316 \mathrm{~L}$ electrode to build the active oxides layer was previously demonstrated [71]). 


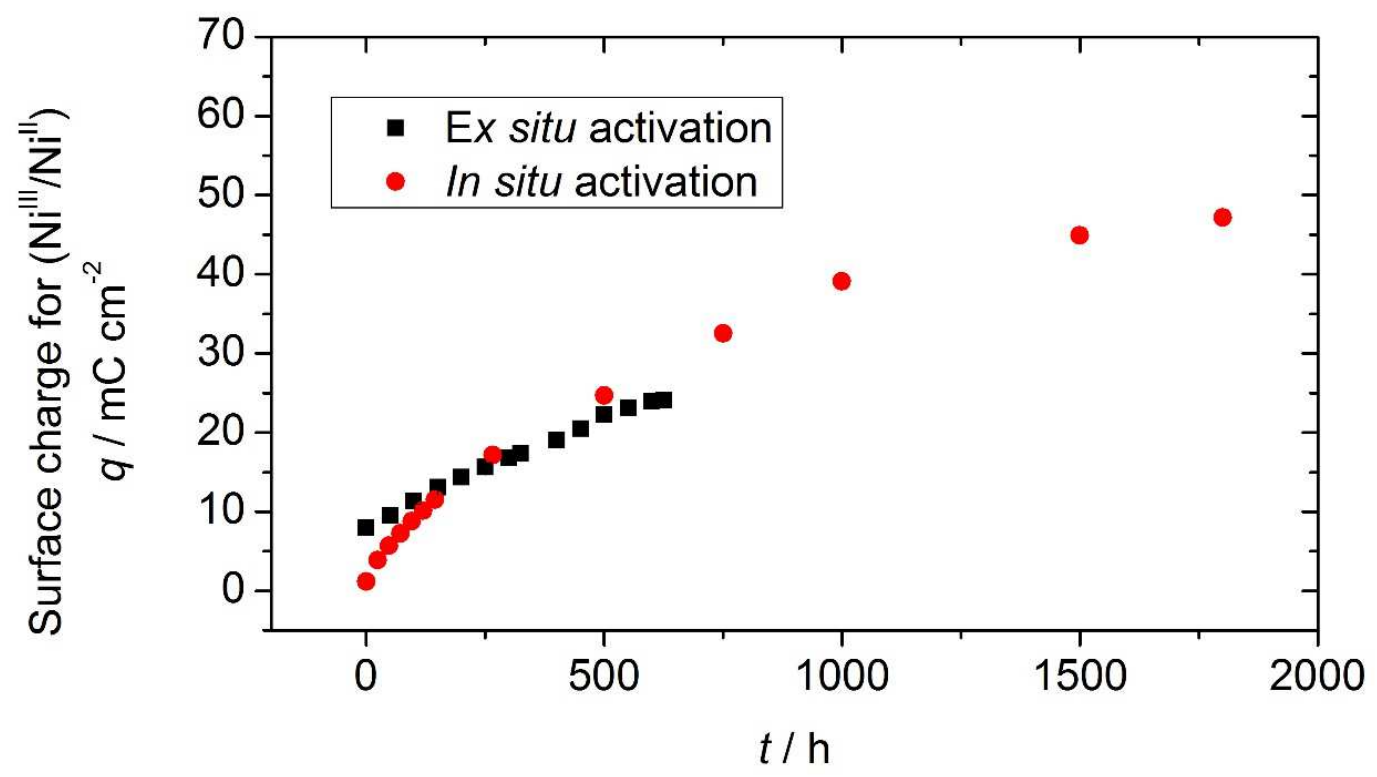

Figure 4: Comparison of the surface charge relative to the NiII/NiIII redox couple as a function of the time of OER operation in $5 \mathrm{M} \mathrm{LiOH}$ at $\mathrm{T}=25^{\circ} \mathrm{C}$, for the $316 \mathrm{~L}$ SS electrodes after accelerated activation or in situ activation (see Figure 2 and 3).

This stable OER activity of the ex situ activated SS electrodes can be linked to its surface morphology, which is rather homogeneous, compact and near-free of defects (Figure 5C,D); in particular, no cracks or surface heterogeneities are seen, which differs from the observations made for an in situ activated electrode (Figure 5A,B). This better integrity of the Ni-rich film formed by ex situ accelerated activation accounts for the better stability of its electrochemical response compared to in situ activated electrodes (Figure 3). In addition, the fact that close to full performances can be reached in less than 9 hours (the duration of the accelerated activation treatment), i.e. 30 times faster than an in situ activation in the same electrolyte, holds great interest for a practical application. 


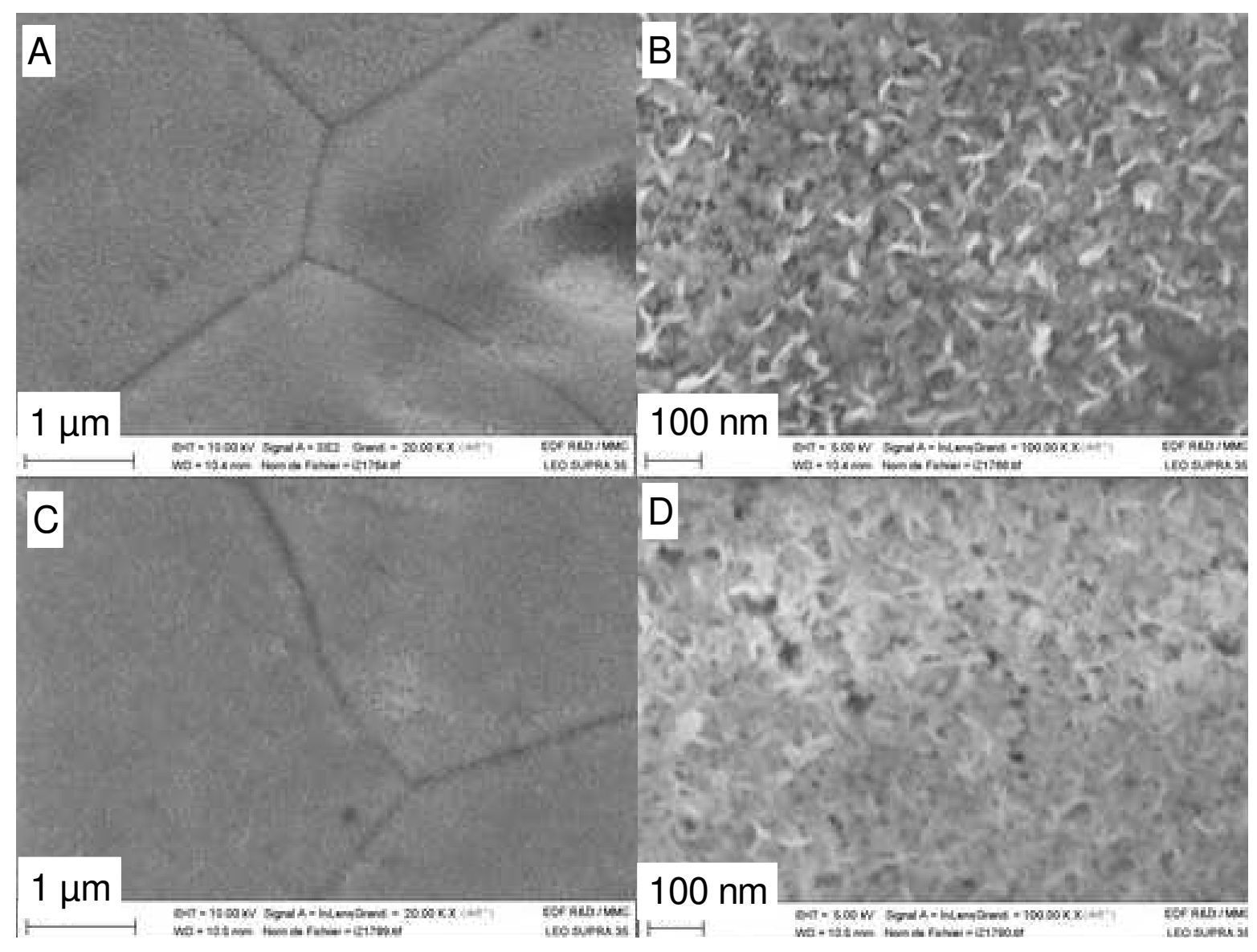

Figure 5: Representative micrographs of the surface of the 316L SS electrode activated $(A, B)$ in situ or $(C, D)$ ex situ by an accelerated procedure. The surface layer of the ex situ-activated electrode is very homogeneous and near-free of defects. Adapted from [85] with permission from Univ. Grenoble- Alpes.

\subsection{OER performances in KOH electrolytes of 316L SS electrodes activated ex situ in $5 \mathrm{M}$} $\mathrm{LiOH}$

The electrochemical performances of 316L SS electrodes activated ex situ in $5 \mathrm{M} \mathrm{LiOH}$ by the accelerated procedure described above were characterized afterwards in $\mathrm{KOH}$ electrolytes, in 
view of a possible application of these electrodes in low-cost and durable alkaline water electrolysis or $\mathrm{KOH}-$ based metal-air batteries. The experiments were performed in a rotating disk configuration (the geometric area of the activated 316L SS electrode was $c a .0 .2 \mathrm{~cm}^{2}$ ); the RDE revolution rate had no effect of on the OER current density monitored in the range $0<j<1 \mathrm{~A}$ $\mathrm{cm}^{-2}$, indicating that mass-transport limitations are not at stake in the present experimental conditions, even at this reasonably high current density (unlike feared in other publications [46, 47] for $\left.j>0.01 \mathrm{~A} \mathrm{~cm}^{-2}\right)$.

The results shown in Figure 6 demonstrate that the 316L SS electrodes activated ex situ by the accelerated procedure in $5 \mathrm{M} \mathrm{LiOH}$ electrolyte are also very active for OER in $\mathrm{KOH}$ electrolytes; the best performances are reached in $1 \mathrm{M} \mathrm{KOH}$, likely owing to (i) the larger oxygen solubility in this electrolyte compared to the others (the solubility of $\mathrm{O}_{2}$ severely decreases at increasing $\mathrm{pH}$ $[91,92]$, leading to larger masking of the electrode by $\mathrm{O}_{2}$ bubbles) and to (ii) the larger water activity in this solution than in the $5 \mathrm{M}$ concentrated hydroxide electrolytes [87]; the performances in $5 \mathrm{M} \mathrm{KOH}$ are also significantly larger than in $5 \mathrm{M} \mathrm{LiOH}$. The fact that $\mathrm{Li}^{+}$ species decrease the OER activity of nickel oxides electrodes, which is why LiOH is a popular electrolyte additive to enhance the cyclability and performances of positive $\mathrm{NiOOH}$ electrodes in alkaline batteries [93, 94], cannot be neglected and could account for these observations. This effect can be explained by the ability of small $\mathrm{Li}^{+}$cations to substitute protons in hydrated forms of metal-oxides, thereby blocking redox transitions and impeding electrocatalytic activity. This was particularly demonstrated for $\mathrm{MnOx} / \mathrm{C}$ oxygen reduction electrocatalysts: in $\mathrm{LiOH}$ electrolyte, the insertion of $\mathrm{Li}^{+}$into the $\mathrm{MnOx}$ lattice stabilizes both the $\mathrm{Mn}$ atoms at the oxidation state 3 and the oxygen groups at the carbon surface, which prevents their role of redox mediating species and further blocks the catalytic process, eventually producing increased ORR 
overpotential values when compared to the activity of the same electrocatalysts in $\mathrm{KOH}$ electrolytes [95].

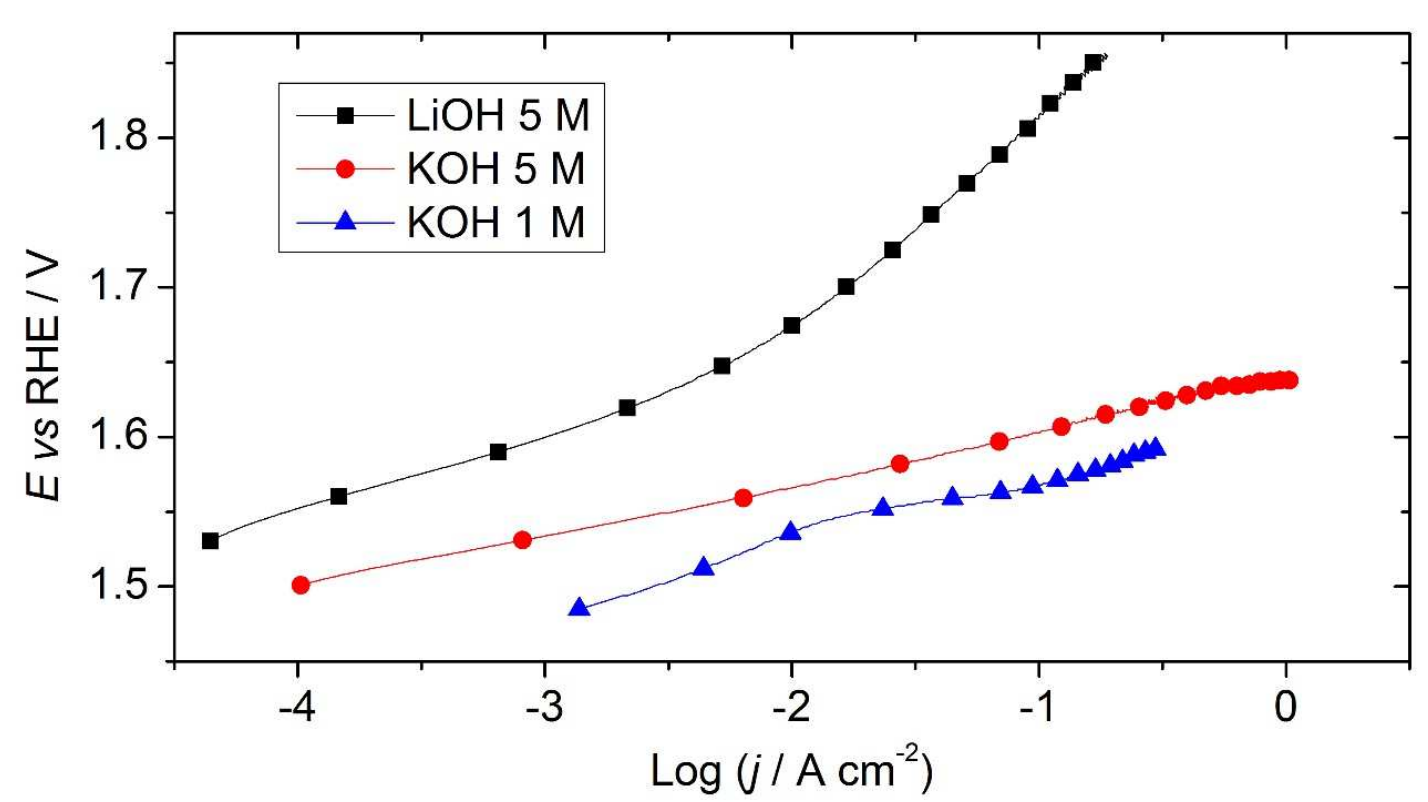

Figure 6: Representative OER voltamperograms measured at 316L electrodes ex situ activated in $5 \mathrm{MLiOH}$ for operation in $5 \mathrm{M} \mathrm{LiOH,} 1 \mathrm{M} \mathrm{KOH}$ or $5 \mathrm{M} \mathrm{KOH}$. In all case, the geometric surface area of the electrode was $S_{\text {geo }}=0.2 \mathrm{~cm}^{2}$, the potential sweep rate $v=0.1 \mathrm{mV} \mathrm{s}^{-1}$ (quasistationary conditions), the temperature maintained at $T=25^{\circ} \mathrm{C}$ and the Ohmic drop compensated.

Such an insertion of the supporting electrolyte cations in the crystalline lattice of the formed surface oxide layer is further demonstrated on Figure 7A,B. Li 1s binding energy is detected upon operation in $5 \mathrm{M} \mathrm{LiOH}$, whereas $\mathrm{K} 2 \mathrm{p} 3 / 2$ is detected upon operation in $5 \mathrm{M} \mathrm{KOH}$. The Raman spectra of Figure $7 \mathrm{C}$ confirms the trend: after operation in $5 \mathrm{M} \mathrm{LiOH}$, the spectra obtained in the region characteristic to the $\mathrm{NiOOH}$ bonds shows a significant blue shift (by 1.4 
and $2.9 \mathrm{~cm}^{-1}$ ), which signals an increase of the strain on the chemical bonds. This excess strain likely originates from the insertion of $\mathrm{Li}^{+}$in the crystalline lattice of $\mathrm{Ni}$-oxides, and the authors speculate that this causes the largely decreased OER activity of the ex situ activated 316L SS electrodes in $5 \mathrm{M} \mathrm{LiOH}$ compared to $\mathrm{KOH}$, as was also reported for the activity of $\mathrm{MnOx} / \mathrm{C}$ based ORR electrocatalysts [95], which was depreciated when operated in LiOH electrolytes.
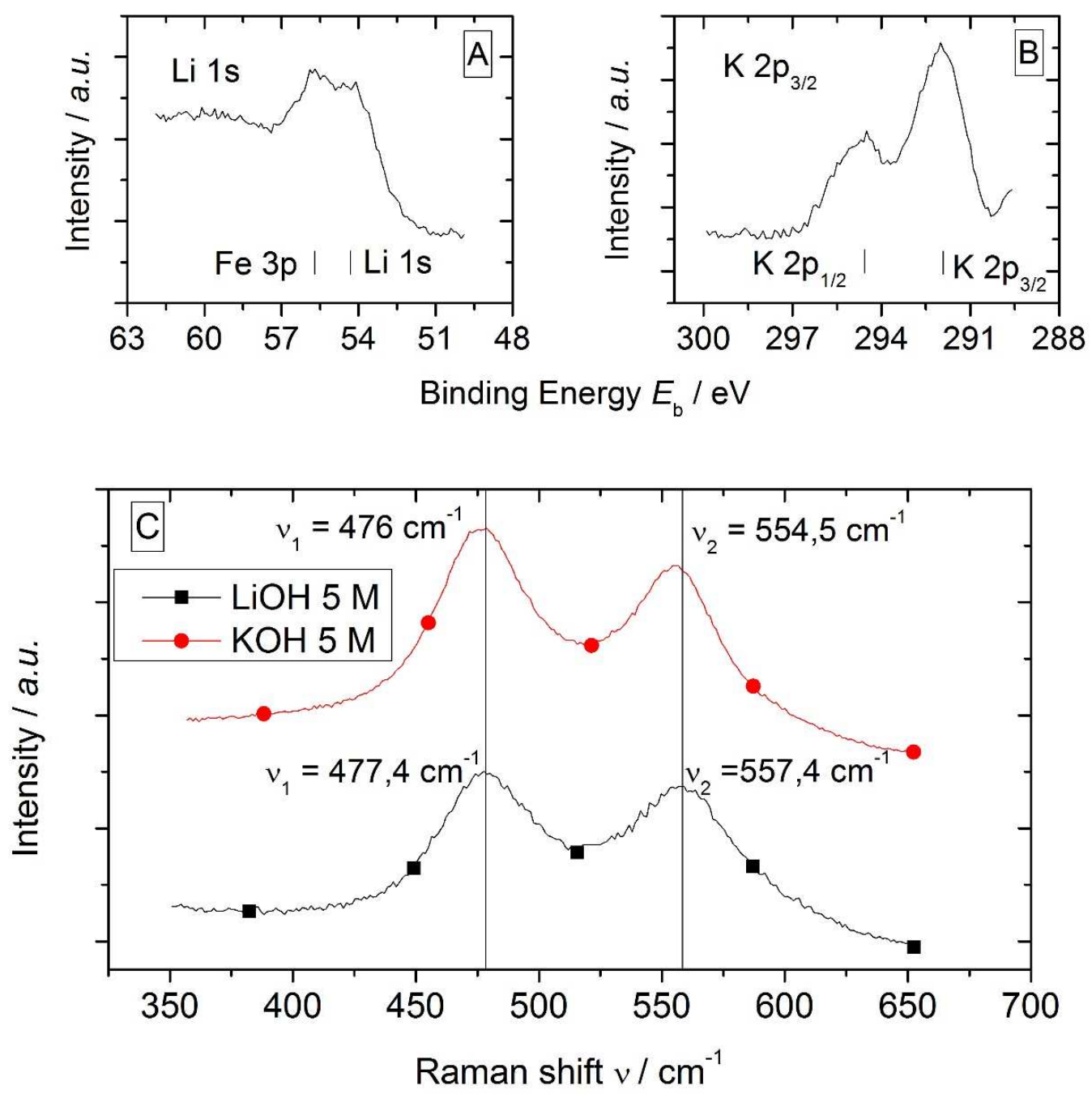

Figure 7: Plots of X-Ray Photoelectron spectroscopy (XPS) of the surface of activated 316L SS electrodes that have undergone OER operation in (A) $5 \mathrm{M} \mathrm{LiOH}$ and (B) $5 \mathrm{M} \mathrm{KOH}$. The X-Ray 
source was $\mathrm{Mg} \mathrm{K \alpha} 1253 \mathrm{eV}$, and the carbon reference peak was set at $284.6 \mathrm{eV} .(\mathrm{C})$

corresponding Raman spectra monitored for the same samples. The spectra were acquired 5 min

after a 1 h-polarization of the electrodes at $E=1.73 \mathrm{~V} v$ s. RHE (Ohmic drop uncompensated).

In $\mathrm{KOH}$ electrolyte, the remarkable activity of the ex situ activated 316L SS electrodes for OER in these conditions is highlighted in Table 2. When the performances are benchmarked to nonnoble-metal OER electrocatalysts (Table 3), it is evident that a properly-activated 316L electrode is very active and competes with state-of-the-art (non-noble) OER materials of the literature. The present electrode is as active or more active than most of these materials, except for a mixed cobalt-lanthanum oxide, for which the OER overvoltage is decreased by $c a . \eta=0.1 \mathrm{~V}$ at $j=100$ $\mathrm{mA} \mathrm{cm}{ }^{-2}$ geometric [22]. Nevertheless, the latter material, elaborated in the form of a thin-film onto a foreign substrate (nickel in that case), would likely experience the durability issues mentioned in preamble of the present study for hetero-deposits (see section 3.1 and Figure 1), issues which should not be at stake for a material with a "self-prepared" active layer like the activated 316L SS electrode [78]. In other words, if this "self-prepared" active layer, made from the very component of the $316 \mathrm{~L}$ SS bulk substrate, degrades upon operation (e.g. from mechanical detachment due to harsh $\mathrm{O}_{2}$ bubbles evolution), it is likely that it will be capable of forming again (there is still plenty of the active material in the bulk of the underlying $316 \mathrm{~L}$ SS material to form new layers). In the literature, to the best of the author's knowledge, only a few paper have presented stability data in OER operation beyond $1000 \mathrm{~h}$; Table 3 for example presents the activity of Janus Ni-Co-P nanowires that have been demonstrated for $3000 \mathrm{~h}$ of OER (and of HER) in $1 \mathrm{M} \mathrm{KOH} \mathrm{(similar} \mathrm{durability} \mathrm{as} \mathrm{for} \mathrm{our} \mathrm{316L} \mathrm{SS} \mathrm{electrode).} \mathrm{The} \mathrm{results} \mathrm{show}$ that these materials fail to meet the activity of our stainless steel electrodes in similar operating 
conditions, demonstrating that the activated 316L SS electrode exhibits a unique combination of high OER activity and long-term durability.

Now, the 316L SS electrodes tested so far have been activated in $5 \mathrm{M} \mathrm{LiOH}$ electrolyte and one would expect a different activity compared to electrodes activated in $\mathrm{KOH}$ electrolyte, because $\mathrm{Li}^{+}$cations likely insert into the NiOx-rich surface layer formed on the bulk 316L SS electrode in the former case, while $\mathrm{K}^{+}$are inserted in the latter (Figure 7). To get around this bias, 316L electrodes were activated in $\mathrm{KOH}$ electrolytes and then tested for the OER.

Table 2: Kinetic parameters of the OER measured in $5 \mathrm{M} \mathrm{LiOH}, 1 \mathrm{M} \mathrm{KOH}$ and $5 \mathrm{M} \mathrm{KOH}$ electrolytes, on the 316L SS electrodes ex situ activated by the accelerated procedure in $5 \mathrm{M}$ LiOH electrolyte.

\begin{tabular}{|c|c|c|c|}
\hline \multirow[t]{2}{*}{ Electrolyte } & \multirow[t]{2}{*}{$\begin{array}{c}\text { Tafel slope / } \mathrm{mV} \\
\mathrm{dec}^{-1}\end{array}$} & \multicolumn{2}{|c|}{ Electrode potential / V vs. RHE } \\
\hline & & $@ j=10 \mathrm{~mA} \mathrm{~cm}^{-2}$ & @ $j=100 \mathrm{~mA} \mathrm{~cm}^{-2}$ \\
\hline $5 \mathrm{M} \mathrm{LiOH}$ & $48-150$ & $\begin{array}{l}1.67 \\
0.44\end{array}$ & $\begin{array}{l}1.81 \\
0.58\end{array}$ \\
\hline $5 \mathrm{M} \mathrm{KOH}$ & 35 & $\begin{array}{l}1.56 \\
0.33\end{array}$ & $\begin{array}{l}1.60 \\
0.37\end{array}$ \\
\hline $1 \mathrm{M} \mathrm{KOH}$ & 42 & 1.53 & 1.56 \\
\hline
\end{tabular}




\begin{tabular}{|c|c|c|c|}
\hline & & 0.3 & 0.33 \\
\hline
\end{tabular}

Table 3: Comparison of the OER performances measured $1 \mathrm{M} \mathrm{KOH}$ on the 316L SS electrodes ex situ activated by the accelerated procedure with several non-noble OER electrocatalysts of the literature. Specific experimental conditions may apply: * extrapolation for a sample characterized in $2 \mathrm{M} \mathrm{KOH}$; \# measured in $0.1 \mathrm{M} \mathrm{KOH} ; \&$ measured at $v=100 \mathrm{mV} \mathrm{s}^{-1}$ (nonstationary experiment)

\begin{tabular}{|c|c|c|}
\hline Electrocatalyst & $\begin{array}{c}\text { Electrode potential / V vs. RHE } \\
\text { Overvoltage / } V \\
\quad j=100 \mathrm{~mA} \mathrm{~cm}^{-2}\end{array}$ & Reference \\
\hline 316L SS ex situ-activated & $\begin{array}{l}1.56 \\
0.33\end{array}$ & This work \\
\hline Oxidized S235steel & $\begin{array}{c}1.70 * \\
0.47\end{array}$ & [73] \\
\hline $\mathrm{NiFe}$ mixed oxides & $\begin{array}{l}1.63 \# \\
0.40\end{array}$ & [96] \\
\hline $\mathrm{Ni}_{45} \mathrm{Fe}_{55} / \mathrm{C}$ nanostructures & $\begin{array}{c}1.55 \& \\
0.32\end{array}$ & [39] \\
\hline
\end{tabular}




\begin{tabular}{|c|c|c|}
\hline $\mathrm{FeMoO}_{4}$ & $\begin{array}{l}1.58-1.60 \\
0.35-0.37\end{array}$ & [97] \\
\hline $\mathrm{Co}_{2.1} \mathrm{Cu}_{0.9} \mathrm{O}_{4}$ & $\begin{array}{l}1.55 \\
0.32\end{array}$ & [98] \\
\hline $\mathrm{Co}_{3} \mathrm{O}_{4}$ (thermal) & $\begin{array}{l}1.73 \\
0.50\end{array}$ & [99] \\
\hline $\mathrm{Co}_{3} \mathrm{La}_{\mathrm{x}} \mathrm{O}_{4}$ (microwave) & $\begin{array}{l}1.47 \\
0.24\end{array}$ & {$[22]$} \\
\hline $\mathrm{Co}_{3} \mathrm{Li}_{\mathrm{x}} \mathrm{O}_{4}$ (sol-gel) & $\begin{array}{l}1.69 \\
0.46\end{array}$ & [100] \\
\hline Electrodeposited mixed Co, Ni oxides & $\begin{array}{l}1.54 \\
0.31\end{array}$ & [101] \\
\hline Janus Ni-Co-P nanowires & $\begin{array}{l}1.59 \\
0.36\end{array}$ & {$[60]$} \\
\hline $\mathrm{Co}_{2} \mathrm{ZnO}_{4}$ & $\begin{array}{l}1.53 \\
0.30\end{array}$ & [102] \\
\hline
\end{tabular}




\subsection{In situ activation of 316L SS electrodes in $\mathrm{KOH}$ electrolytes and their OER performances in $\mathrm{KOH}$ electrolytes}

Polarizing of a non-activated 316L SS electrode in $5 \mathrm{M} \mathrm{KOH}$ (Figure S1A in supporting information) shows comparable behavior to that in $5 \mathrm{M} \mathrm{LiOH}$ : the OER current density progressively increases for the first $c a .50 \mathrm{~h}$ and then plateaus, as a result of a surface-enrichment in nickel oxides during the first $250 \mathrm{~h}$ of test (Figure S1B). This film of nickel oxides has a rather rough texture (Figure S1C), an amorphous nature (Figure S2) and is composed of mixed oxides of $\mathrm{Ni}, \mathrm{Fe}$ and $\mathrm{Cr}$ (Figure S3). The elemental analyses show that there is very little difference (in terms of composition in transition metal cations) in the active surface layer formed in $\mathrm{KOH}$ electrolyte (Table S1) compared to that formed in LiOH electrolyte [71].

The OER performances obtained after in situ activation in $5 \mathrm{M} \mathrm{KOH}\left(c a . j=350 \mathrm{~mA} \mathrm{~cm}^{-2}\right.$ at $E=$ $1.63 \mathrm{~V} v s$. RHE, $\eta=0.4 \mathrm{~V}$, see Figure S1) can be compared to those obtained for the $316 \mathrm{~L}$ electrode activated ex situ in $5 \mathrm{M} \mathrm{LiOH}$ and tested in $5 \mathrm{M} \mathrm{KOH}\left(c a . j=550 \mathrm{~mA} \mathrm{~cm}^{-2}\right.$ at $E=1.63$ V vs. RHE, $\eta=0.4 \mathrm{~V}$ ) (see Figure 6). These data demonstrate that the ex situ activation in $5 \mathrm{M}$ $\mathrm{LiOH}$ by the accelerated procedure is very efficient to prepare highly-active $316 \mathrm{~L}$ electrodes for the OER, whatever the electrolyte composition of the medium in which the OER is performed. The next section will study whether electrodes prepared in an accelerated manner by ex situ activation in $\mathrm{KOH}$ are also very active for OER operation in $\mathrm{LiOH}$ electrolytes.

3.5. OER performances in $5 \mathrm{M} \mathrm{LiOH} \mathrm{of} \mathrm{316L} \mathrm{SS} \mathrm{electrodes} \mathrm{activated} \mathrm{ex} \mathrm{situ} \mathrm{in} 5 \mathrm{M} \mathrm{KOH}$

316L SS electrode activated ex situ in $5 \mathrm{M} \mathrm{KOH}$ before long-term operation in $5 \mathrm{M} \mathrm{LiOH}$ (Figure S4) exhibit initial performances which are roughly twice larger than those for a 316L SS 
electrode activated in situ or ex situ in $5 \mathrm{M} \mathrm{LiOH}$ (see Figure 3). Based on Figure 7 and Table $\mathrm{S} 1$, these superior performances upon ex situ activation in $5 \mathrm{M} \mathrm{KOH}$, may be accounted for by the presence of $\mathrm{K}^{+}$in the hydrated oxide layers (instead of $\mathrm{Li}^{+}$), an enrichment of iron in the oxide layer and a larger active surface area (more details are available in supporting information). However, the catalytic layer formed by ex situ activation in $5 \mathrm{M} \mathrm{KOH}$ is not stable under long-term OER operation in $5 \mathrm{M} \mathrm{LiOH}$ electrolyte (Figure S4A); the surface charge related to the NiII/NiIII transition increases (Figure S4B) until the performances reached become comparable to those obtained after in situ activation in $5 \mathrm{M} \mathrm{LiOH}$ (see Figure 1 and Figure 3). In other words, the catalytic layer formed ex situ in $5 \mathrm{M} \mathrm{KOH}$ spontaneously and gradually evolves towards a different (and less active) state upon operation in $\mathrm{LiOH}$ electrolytes. This further confirms that only electrodes activated in the same environment than their environment of usage have stable performances in operation, even if activation in $\mathrm{KOH}$ yields larger initial performances of OER, whatever the medium of OER operation.

\subsection{Ex situ activation of 316L SS electrodes in KOH or LiOH electrolytes and their OER performances in $\mathrm{KOH}$ electrolytes}

A 316L stainless steel electrode ex situ-activated in $5 \mathrm{M} \mathrm{KOH}$ using the accelerated procedure described in section 3.2 exhibits equivalent behavior as that obtained after (much longer) in situ activation (Figure S5): the OER is stable over 1000+ hours of test. However, the electrode activated ex situ in $5 \mathrm{M} \mathrm{LiOH}$ is less active than that activated in $5 \mathrm{M} \mathrm{KOH}$ : activation in $\mathrm{KOH}$ is always preferable in terms of OER activity, whatever the electrolyte of final usage, probably because $\mathrm{Li}^{+}$species are rather-irreversibly inserted in the NiOx layer, on the contrary to $\mathrm{K}^{+}$. 


\section{Conclusions}

This paper demonstrates that it is possible to activate a 316L stainless steel electrode for OER without using hetero-elements and without making deposits on the surface of the electrode. The activation step is not only possible by spontaneous (usually slow) evolution of the surface composition/structure in the medium of OER operation, but it can be accelerated by using a properly-designed procedure (e.g. succession of potential steps of "oxidation" and "reduction" of the surface). The present approach fundamentally differs from that usually used in electrocatalysis, where compounds of tailored composition/structure/texture are added/deposited at a conductive substrate, their initial activity being optimal but their long-term stability not being guaranteed in the harsh operating conditions of an OER electrode (mechanical stress due to bubbles + highly-oxidizing conditions). In the approach detailed herein, the catalytic surface is created from the bulk components of the stainless steel electrode in experimental conditions that are close to those of usage, which is inherently more favorable to the long-term stability of the prepared surfaces.

It has been observed that $\mathrm{KOH}_{(\mathrm{aq})}$ is a better electrolyte for activation than $\mathrm{LiOH}_{(\mathrm{aq})}$, whatever the final alkaline electrolyte used, but activating in the final electrolyte could be more practical and shall give the same results in the (very) long run. Besides, the OER performances reached in alkaline electrolytes for the materials activated by an ex situ accelerated procedure compare well to those obtained for the same materials activated in situ, the latter being a much more timeconsuming procedure. In particular, the performance of activated $316 \mathrm{~L}$ electrodes in $\mathrm{KOH}$ electrolytes compare favorably to those of state-of-the-art OER materials of the literature in 
similar environments, the latter being prepared by depositing active layers at the surface of a conducting substrate. More importantly, the $316 \mathrm{~L}$ electrodes did not show significant degradation in performance and surface over a few 100s of hours of OER operation, which should be highlighted given the very large current densities experienced (a few 100s of mA cm $\left.{ }^{2}\right)$.

This suggests that stainless steel electrodes could prove to be good OER materials for use in alkaline water electrolyzers, even if this needs to be confirmed for longer duration of operation, larger active areas and non-flat surfaces (e.g. mesh, felts or grids). As a result, this paper opens the way to the development of highly-active and low-cost OER materials for the production of hydrogen (and in particular for the oxygen evolution reaction), but also as charging electrode in KOH-based metal-air batteries.

\section{ASSOCIATED CONTENT}

There is no associated content for this contribution.

\section{AUTHOR INFORMATION}

Florian Moureaux: moureaux.florian@hotmail.fr

Philippe Stevens: philippe.stevens@edf.fr

Gwénaëlle Toussaint: gwenaelle.toussaint@edf.fr 
Marian Chatenet: Marian.Chatenet@grenoble-inp.fr; personal webpage : http://lepmi.grenobleinp.fr/personnels/m-chatenet-marian--429692.kjsp; team webpage: http://lepmi.grenobleinp.fr/team-eip/interfacial-electrochemistry-and-processes-team-eip--754099.kjsp

\section{ACKNOWLEDGEMENT}

This work was performed within the framework of the Centre of Excellence of Multifunctional Architectured Materials "CEMAM" n॰ AN-10-LABX-44-01. MC thanks the French Institut Universitaire de France "IUF" for its support and Stéphane Coindeau, Thierry Encinas, Frédéric Charlot and Grégory Berthomé (from the Consortium des Moyens Technologiques Communs (CMTC) of Grenoble-INP) for the XRD, FEG-SEM and XPS characterizations, as well as Michel Mermoux for the Raman analyses.

\section{REFERENCES}

[1] A.F. Ghoniem, Prog. Energ. Comb. Sci. 37 (2011) 15-51.

[2] P.T. Moseley, J. Garche, Electrochemical Energy Storage for Renewable Sources and Grid Balancing, Elsevier, Amsterdam, 2015.

[3] J.M. Tarascon, M. Armand, Nature 414 (2001) 359-367.

[4] P.G. Bruce, S.A. Freunberger, L.J. Hardwick, J.M. Tarascon, Nat. Mater. 11 (2012) 1929.

[5] F. Meng, H. Zhong, D. Bao, J. Yan, X. Zhang, J. Am. Chem. Soc. 138 (2016) 1022610231.

[6] M. Götz, J. Lefebvre, F. Mörs, A. McDaniel Koch, F. Graf, S. Bajohr, R. Reimert, T. Kolb, Renew. Energy 85 (2016) 1371-1390.

[7] C. Mittelsteadt, T. Norman, M. Rich, J. Willey, in: P.T. Moseley, J. Garche (Eds.), Electrochemical Energy Storage for Renewable Sources and Grid Balancing, Elsevier, Amsterdam, 2015, pp. 159-181.

[8] M. Carmo, D.L. Fritz, J. Mergel, D. Stolten, Int. J. Hydrogen Energy 38 (2013) 49014934. 
[9] R. Tunold, A.T. Marshall, E. Rasten, M. Tsypkin, L.E. Owe, S. Sunde, Materials for electrocatalysis of oxygen evolution process in PEM water electrolysis cells, ECS Trans., 23 ed., 2010, pp. 103-117.

[10] S.A. Grigoriev, P. Millet, V.N. Fateev, J. Power Sources 177 (2008) 281-285.

[11] I.A. Lervik, M. Tsypkin, L.E. Owe, S. Sunde, J. Electroanal. Chem. 645 (2010) 135-142.

[12] S. Sunde, I.A. Lervik, M. Tsypkin, L.E. Owe, Electrochim. Acta 55 (2010) 7751-7760.

[13] F. Ye, J. Li, X. Wang, T. Wang, S. Li, H. Wei, Q. Li, E. Christensen, Int. J. Hydrogen Energy 35 (2010) 8049-8055.

[14] L.E. Owe, M. Tsypkin, K.S. Wallwork, R.G. Haverkamp, S. Sunde, Electrochim. Acta 70 (2012) 158-164.

[15] L. Wang, Y. Zhu, Z. Zeng, C. Lin, M. Giroux, L. Jiang, Y. Han, J. Greeley, C. Wang, J. Jin, Nano Energy 31 (2017) 456-461.

[16] S. Cherevko, T. Reier, A.R. Zeradjanin, Z. Pawolek, P. Strasser, K.J.J. Mayrhofer, Electrochem. Commun. 48 (2014) 81-85.

[17] S. Cherevko, A. Topalov, A. Zeradjanin, G. Keeley, K.J. Mayrhofer, Electrocatal. 5 (2014) 235-240.

[18] S. Cherevko, A.R. Zeradjanin, G.P. Keeley, K.J.J. Mayrhofer, J. Electrochem. Soc. 161 (2014) H822-H830.

[19] S. Cherevko, S. Geiger, O. Kasian, N. Kulyk, J.P. Grote, A. Savan, B.R. Shrestha, S. Merzlikin, B. Breitbach, A. Ludwig, K.J.J. Mayrhofer, Catal. Today 262 (2016) 170-180.

[20] S. Geiger, O. Kasian, A.M. Mingers, K.J.J. Mayrhofer, S. Cherevko, Sci. Rep. 7 (2017).

[21] D.E. Hall, J. Electrochem. Soc. 132 (1985) 41C-48C.

[22] R.N. Singh, D. Mishra, Anindita, A.S.K. Sinha, A. Singh, Electrochem. Commun. 9 (2007) 1369-1373.

[23] S. Marini, P. Salvi, P. Nelli, R. Pesenti, M. Villa, M. Berrettoni, G. Zangari, Y. Kiros, Electrochim. Acta 82 (2012) 384-391.

[24] W.F. Chen, C.H. Wang, K. Sasaki, N. Marinkovic, W. Xu, J.T. Muckerman, Y. Zhu, R.R. Adzic, Energy Environ. Sci. 6 (2013) 943-951.

[25] X. Wang, Y.V. Kolen'Ko, X.Q. Bao, K. Kovnir, L. Liu, Angew. Chem. Int. Ed. 54 (2015) 8188-8192.

[26] Y. Yang, D. Xu, Q. Wu, M. Xiang, P. Diao, Beijing Hangkong Hangtian Daxue Xuebao/Journal of Beijing University of Aeronautics and Astronautics 41 (2015) 2158-2165.

[27] M.K. Bates, Q. Jia, H. Doan, W. Liang, S. Mukerjee, ACS Catal. 6 (2016) 155-161.

[28] Y.H. Chung, K. Gupta, J.H. Jang, H.S. Park, I. Jang, Y.K. Lee, S.C. Lee, S.J. Yoo, Nano Energy 26 (2016) 496-503.

[29] J. Li, X. Zhou, Z. Xia, W. Gao, Y. Ma, Y. Qu, ACS Applied Materials and Interfaces 8 (2016) 10826-10834.

[30] K. Liu, W. Zhang, F. Lei, L. Liang, B. Gu, Y. Sun, B. Ye, W. Ni, Y. Xie, Nano Energy 30 (2016) 810-817.

[31] Y.Y. Ma, C.X. Wu, X.J. Feng, H.Q. Tan, L.K. Yan, Y. Liu, Z.H. Kang, E.B. Wang, Y.G. Li, Energy Environ. Sci. 10 (2017) 788-798.

[32] T. Wang, X. Wang, Y. Liu, J. Zheng, X. Li, Nano Energy 22 (2016) 111-119.

[33] J. Divisek, J. Mergel, H. Schmitz, Int. J. Hydrogen Energy 7 (1982) 695-701.

[34] H. Wendt, G. Imarisio, J. Appl. Electrochem. 18 (1988) 1-14.

[35] A. Ursúa, L.M. Gandía, P. Sanchis, Proceedings of the IEEE 100 (2012) 410-426. 
[36] J. Mergel, W. Maier, D. Stolten, Hydrogen production by water electrolysis: A review of the current status and future trends, 20th World Hydrogen Energy Conference, WHEC 2014, 2014, pp. 1165-1169.

[37] F. Dionigi, P. Strasser, Advanced Energy Materials 6 (2016).

[38] M. Görlin, M. Gliech, J.F. De Araújo, S. Dresp, A. Bergmann, P. Strasser, Catal. Today 262 (2016) 65-73.

[39] M. Gorlin, J.F. De Araujo, H. Schmies, D. Bernsmeier, S. Dresp, M. Gliech, Z. Jusys, P. Chernev, R. Kraehnert, H. Dau, P. Strasser, J. Am. Chem. Soc. 139 (2017) 2070-2082.

[40] J. Wang, K. Li, H.-x. Zhong, D. Xu, Z.-1. Wang, Z. Jiang, Z.-j. Wu, X.-b. Zhang, Angewandte Chemie International Edition 54 (2015) 10530-10534.

[41] P.W. Menezes, A. Indra, D. González-Flores, N.R. Sahraie, I. Zaharieva, M. Schwarze, P. Strasser, H. Dau, M. Driess, ACS Catal. 5 (2015) 2017-2027.

[42] P.W. Menezes, A. Indra, N.R. Sahraie, A. Bergmann, P. Strasser, M. Driess, ChemSusChem 8 (2015) 164-171.

[43] P.W. Menezes, A. Indra, N.R. Sahraie, A. Bergmann, P. Strasser, M. Driess, ChemSusChem 8 (2015) 164-167.

[44] F. Dionigi, T. Reier, Z. Pawolek, M. Gliech, P. Strasser, ChemSusChem 9 (2016) $962-$ 972.

[45] M. Gliech, A. Bergmann, C. Spöri, P. Strasser, Journal of Energy Chemistry 25 (2016) 278-281.

[46] C.C.L. McCrory, S. Jung, J.C. Peters, T.F. Jaramillo, J. Am. Chem. Soc. 135 (2013) 16977-16987.

[47] S. Jung, C.C.L. McCrory, I.M. Ferrer, J.C. Peters, T.F. Jaramillo, J. Mater. Chem. A 4 (2016) 3068-3076.

[48] M.K. Bates, Q. Jia, H. Doan, W. Liang, S. Mukerjee, ACS Catal. (2015).

[49] N. Li, W.Y. Xia, J. Wang, Z.L. Liu, Q.Y. Li, S.Z. Chen, C.W. Xu, X.H. Lu, J. Mater. Chem. A 3 (2015) 21308-21313.

[50] M.H. Miles, Y.H. Huang, S. Srinivasan, J. Electrochem. Soc. 125 (1978) 1931-1934.

[51] V.A. Alves, L.A. Da Silva, J.F.C. Boodts, Electrochim. Acta 44 (1998) 1525-1534.

[52] Y.L. Lo, S.C. Chou, B.J. Hwang, J. Appl. Electrochem. 26 (1996) 733-740.

[53] E. Rios, P. Chartier, J.L. Gautier, Solid State Sciences 1 (1999) 267-277.

[54] R. Berenguer, J.M. Sieben, C. Quijada, E. Morallón, ACS Applied Materials and Interfaces 6 (2014) 22778-22789.

[55] X.X. Ma, X.Q. He, RSC Adv. 6 (2016) 50017-50026.

[56] E. Laouini, M. Hamdani, M.I.S. Pereira, J. Douch, M.H. Mendonça, Y. Berghoute, R.N. Singh, J. Appl. Electrochem. 38 (2008) 1485-1494.

[57] M. Dinamani, P.V. Kamath, J. Appl. Electrochem. 30 (2000) 1157-1161.

[58] L.F. Arenas, C. Ponce de León, F.C. Walsh, Electrochem. Commun. 77 (2017) 133-137.

[59] A. Balram, H. Zhang, S. Santhanagopalan, ACS Applied Materials and Interfaces 9 (2017) 28355-28365.

[60] W. Li, X. Gao, X. Wang, D. Xiong, P.-P. Huang, W.-G. Song, X. Bao, L. Liu, J. Power Sources 330 (2016) 156-166.

[61] P.N. Ross, H. Sokol, J. Electrochem. Soc. 131 (1984) 1742-1750.

[62] N. Staud, P.N. Ross, J. Electrochem. Soc. 133 (1986) 1079-1084.

[63] P.N. Ross, M. Sattler, J. Electrochem. Soc. 135 (1988) 1464-1470.

[64] N. Staud, H. Sokol, P.N. Ross, J. Electrochem. Soc. 136 (1989) 3570-3576. 
[65] A. Zadick, L. Dubau, M. Chatenet, U. Demirci, A. Serov, P. Atanassov, ECS Trans. 69 (2015) 553-558.

[66] A. Zadick, L. Dubau, N. Sergent, G. Berthomé, M. Chatenet, ACS Catal. 5 (2015) 48194824.

[67] A. Zadick, L. Dubau, U.B. Demirci, M. Chatenet, J. Electrochem. Soc. 163 (2016) F781F787.

[68] I. Roche, E. Chainet, J. Vondrak, M. Chatenet, J. Appl. Electrochem. 38 (2008) 11951201.

[69] M. Chatenet, L. Génies-Bultel, M. Aurousseau, R. Durand, F. Andolfatto, J. Appl. Electrochem. 32 (2002) 1131-1140.

[70] M. Chatenet, M. Aurousseau, R. Durand, F. Andolfatto, J. Electrochem. Soc. 150 (2003) D47-D55.

[71] F. Moureaux, P. Stevens, G. Toussaint, M. Chatenet, J. Power Sources 229 (2013) 123132.

[72] H. Schäfer, S.M. Beladi-Mousavi, L. Walder, J. Wollschläger, O. Kuschel, S. Ichilmann, S. Sadaf, M. Steinhart, K. Küpper, L. Schneider, ACS Catal. 5 (2015) 2671-2680.

[73] H. Schäfer, K. Küpper, J. Wollschläger, N. Kashaev, J. Hardege, L. Walder, S. Mohsen Beladi-Mousavi, B. Hartmann-Azanza, M. Steinhart, S. Sadaf, F. Dorn, ChemSusChem 8 (2015) 3099-3110.

[74] H. Schäfer, S. Sadaf, L. Walder, K. Kuepper, S. Dinklage, J. Wollschläger, L. Schneider, M. Steinhart, J. Hardege, D. Daum, Energy Environ. Sci. 8 (2015) 2685-2697.

[75] H. Schäfer, D.M. Chevrier, K. Kuepper, P. Zhang, J. Wollschlaeger, D. Daum, M. Steinhart, C. Heß, U. Krupp, K. Müller-Buschbaum, J. Stangl, M. Schmidt, Energy Environ. Sci. 9 (2016) 2609-2622.

[76] H. Schäfer, D.M. Chevrier, P. Zhang, J. Stangl, K. Müller-Buschbaum, J.D. Hardege, K. Kuepper, J. Wollschläger, U. Krupp, S. Dühnen, M. Steinhart, L. Walder, S. Sadaf, M. Schmidt, Advanced Functional Materials 26 (2016) 6402-6417.

[77] H. Zhong, J. Wang, F. Meng, X. Zhang, Angewandte Chemie International Edition 55 (2016) 9937-9941.

[78] H. Schäfer, M. Chatenet, ACS Energy Letters (2018).

[79] D. Tang, O. Mabayoje, Y. Lai, Y. Liu, C.B. Mullins, ChemistrySelect 2 (2017) 22302234.

[80] J.S. Sagu, K.G.U. Wijayantha, M. Bohm, S. Bohm, T. Kumar Rout, ACS Applied Materials and Interfaces 8 (2016) 6277-6285.

[81] Z. Wu, W. Qiu, Y. Chen, Y. Luo, Y. Huang, Q. Lei, S. Guo, P. Liu, M.S. Balogun, Y. Tong, J. Mater. Chem. A 5 (2017) 756-764.

[82] A. Serov, I.V. Zenyuk, C.G. Arges, M. Chatenet, J. Power Sources 375 (2018) 149-157.

[83] N. Spataru, C. Terashima, K. Tokuhiro, I. Sutanto, D.A. Tryk, S.-M. Park, A. Fujishima, J. Electrochem. Soc. 150 (2003) E337-E341.

[84] G. Gardner, J. Al-Sharab, N. Danilovic, Y.B. Go, K. Ayers, M. Greenblatt, G. Charles Dismukes, Energy Environ. Sci. 9 (2016) 184-192.

[85] F. Moureaux, Etude des réactions mettant en jeu l'oxygène dans un système électrochimique lithium-air aqueux rechargeable électriquement, LEPMI, Grenoble-INP, Grenoble, 2011.

[86] N.K. Singh, J.P. Singh, R.N. Singh, Int. J. Hydrogen Energy 27 (2002) 895-903.

[87] B.G. Pound, R.P. Singh, D.D. Macdonald, J. Power Sources 18 (1986) 1-31. 
[88] J.O. Bockris, A.K.N. Reddy, B. Rao, J. Electrochem. Soc. 113 (1966) 1133-1144.

[89] M.M. Jaksic, Solid State Ionics 136-137 (2000) 733-746.

[90] F. Micoud, Influence d'un support $\mathrm{MOx}(\mathrm{M}=\mathrm{W}, \mathrm{Ti})$ sur les propriétés électrocatalytiques de nanoparticules de platine, LEPMI, Grenoble-INP, Grenoble, 2009, p. 213.

[91] M. Chatenet, M. Aurousseau, R. Durand, Ind. Eng. Chem. Res. 39 (2000) 3083-3089.

[92] M. Chatenet, M. Aurousseau, R. Durand, Electrochim. Acta 45 (2000) 2823-2827.

[93] D.M. Constantin, E.M. Rus, L. Oniciu, L. Ghergari, J. Power Sources 74 (1998) 188-197.

[94] C. Greaves, M.A. Thomas, M. Turner, J. Power Sources 12 (1984) 195-202.

[95] F. Moureaux, P. Stevens, M. Chatenet, Electrocatal. 4 (2013) 123-133.

[96] M. Görlin, P. Chernev, J.F. De Araújo, T. Reier, S. Dresp, B. Paul, R. Krähnert, H. Dau, P. Strasser, J. Am. Chem. Soc. 138 (2016) 5603-5614.

[97] R.N. Singh, Madhu, R. Awasthi, S.K. Tiwari, Int. J. Hydrogen Energy 34 (2009) 46934700.

[98] B. Marsan, N. Fradette, G. Beaudoin, J. Electrochem. Soc. 139 (1992) 1889-1896.

[99] S.P. Singh, S. Samuel, S.K. Tiwari, R.N. Singh, Int. J. Hydrogen Energy 21 (1996) 171178.

[100] F. Švegl, B. Orel, I. Grabec-Švegl, V. Kaučič, Electrochim. Acta 45 (2000) 4359-4371.

[101] G. Wu, N. Li, D.R. Zhou, K. Mitsuo, B.Q. Xu, J. Solid State Chem. 177 (2004) 36823692.

[102] B. Chi, J. Li, X. Yang, H. Lin, N. Wang, Electrochim. Acta 50 (2005) 2059-2064. 